\title{
Exposure to Common Anesthetic Agents Alters Pup-retrieval Response in Lactating Rats
}

\author{
Yutaka YAMAMURO \\ Department of Animal Science, College of Bioresource Sciences, Nihon University, \\ Fujisawa, Kanagawa 252-8510, Japan
}

\begin{abstract}
This study investigated the lactating stage of rats to determine the effect on maternal behavior of a single exposure to general anesthetic. Lactating Wistar rats were treated with anesthetic doses of pentobarbital (PENT) or ketamine (KET) on day 3 or 9 of lactation, and their behavioral responses were evaluated during a 50-min nursing period, after a 4-h mother-pup separation, on day 12. Exposure to KET on day 9 led to a significantly longer latency to pup-retrieval than that of the control. Duration of pup-retrieval in mothers treated with KET on day 3 and 9 was significantly longer than in the control. Other components of maternal behavior did not differ between the groups. The present findings suggested that general anesthetics have an impact upon pup-retrieval activities, which indirectly represent maternal motivation.
\end{abstract}

Key words: general anesthetics, lactating rats, pup-retrieval

The expression of maternal performance has generally been considered innate behavior, distinct from acquired behavior such as the majority of learning tasks. However, we recently confirmed that some components of maternal behavior, pup-retrieval and self-grooming, etc., which can be used to evaluate the motivational and emotional status of the mother, were quite different in the early stage of lactation from those in the middle or established stage of lactation [30], suggesting that the established maternal performance depends upon the alteration of maternal emotionality with the progression of the postpartum stage.

In laboratory animals, general anesthetics are indispensable in surgical operations. Presently used anesthetic drugs act by two principal mechanisms: (a) an increase in inhibition via $\mathrm{GABA}_{\mathrm{A}}$ receptors [8], and (b) a decrease in excitation through NMDA receptors [7]. Exposure to anesthetic agents results in the alteration of several behavioral aspects after wakefulness from anesthesia for longer than predicted by the pharmacology of the drugs used $[22,31]$. The implication is that common anesthetic drugs have psychotomimetic actions [13, 25], which differ from the primary action as an anesthetic. However, the influence on maternal behavior has not yet been investigated. The objective of the present study was to examine whether exposure to the general anesthetic drugs, ketamine (KET), a noncompetitive NMDA glutamate receptor antagonist, and pentobarbital (PENT), which acts as a $\mathrm{GABA}_{\mathrm{A}}$ receptor agonist, has an impact on maternal performance during

(Received 7 December 2004 / Accepted 22 April 2005)

Address corresponding: Y. Yamamuro, Department of Animal Science, College of Bioresource Sciences, Nihon University, 1866 Kameino, Fujisawa, Kanagawa 252-8510, Japan 

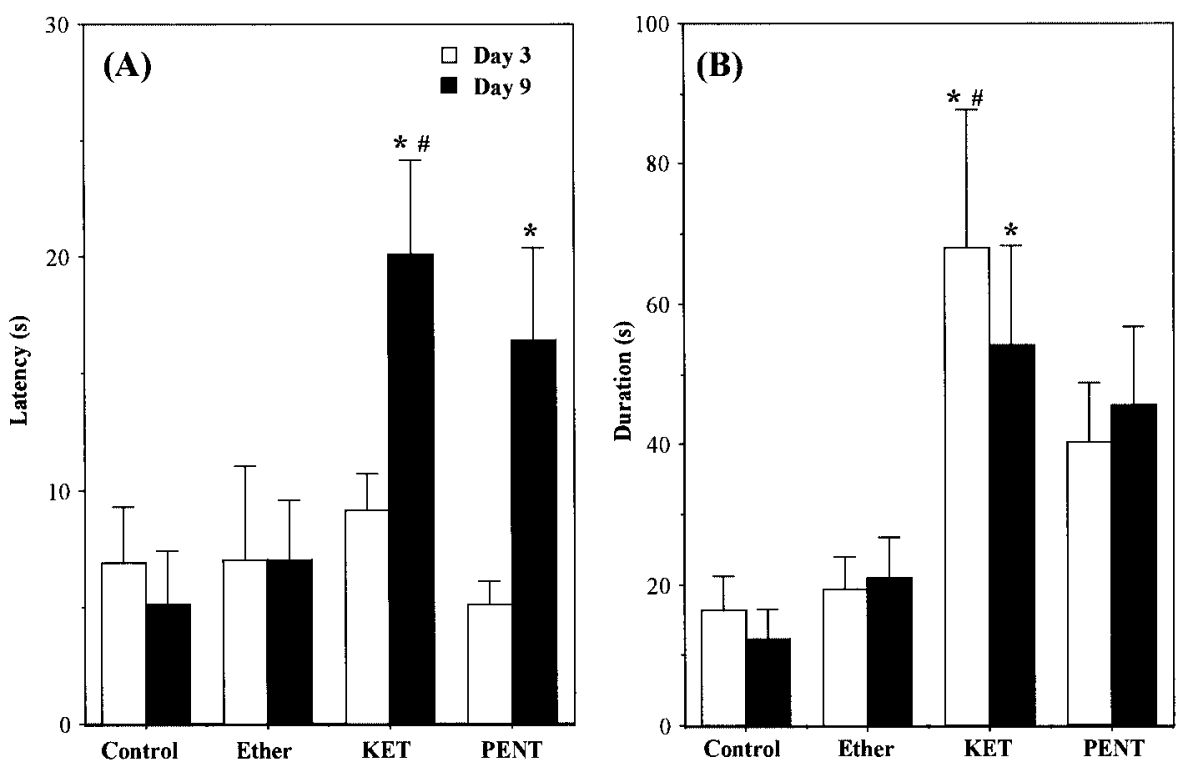

Fig. 1. Latency to the onset (A) and duration (B) of pup-retrieval during a 50-min nursing period on day 12 of lactation. Values are means \pm SEM. Significant differences were indicated as * (vs. Control), \# (vs. Ether) at $P<0.05$ on each day of treatment.

the established stage of lactation in rats.

Wistar rats ( $\mathrm{Jcl}:$ Wistar) were purchased and maintained with a random mating in our laboratory. Seventy-nine nulliparous female rats were obtained from our breeding colony. They were mated with male Wistar rats aged 3-4 months and moved to individual plastic cages $(310 \times 250 \times 180 \mathrm{~mm})$ after spermatozoa were found in vaginal smears (day 1 of gestation). The pregnant rats were housed at $23 \pm 1^{\circ} \mathrm{C}$ under a photoperiod of $14 \mathrm{~h}$ light: $10 \mathrm{~h}$ dark (light on at $0600 \mathrm{~h}$ ). At $0900 \mathrm{~h}$ on day 1 of lactation (the day after parturition), each litter was adjusted to 8 pups. The body weight of pups was measured once daily $(0900 \mathrm{~h})$ until the end of the experiment. All experiments conformed to the Guideline for Animal Experiments, College of Bioresource Sciences, Nihon University.

On day 3 or 9 of lactation, mothers were isolated from their litters at $1000 \mathrm{~h}$, and injected i.p. with PENT (35 mg/kg body weight; Nembutal Sodium Solution, Abbott Laboratories, Il, USA) or KET (50 mg/kg body weight, KetalarTM; ketamine hydrochloride, Sankyo Co. Ltd., Tokyo, Japan) under light ether anesthesia. Three hours later, after confirmation of awakening, mothers were returned to their home cages. The other rats were also isolated from their litters for $3 \mathrm{~h}$ with no treatments (control) or with a light ether anesthesia for $1 \mathrm{~h}$
(Ether) on day 3 or 9 of lactation. On day 12, litters were separated from their mothers at $1000 \mathrm{~h}$. After separation for $4 \mathrm{~h}$, litters were returned to the center of the mother's cage. During a nursing period of 50-min, the behavioral responses were recorded on videotape with a CCD camera. The procedure for determination of pup-directed and non pup-directed activities was the same as that described in detail by Yamamuro et al. [30]. Statistical significance was based on two-way ANOVA and analysis between groups was tested with subsequent planned comparisons, which contrasts the mean comparisons of selected levels of a factor, using statistical software, Super ANOVA (Abacus Concepts, Inc., CA, USA). A $P$ value $<0.05$ was considered significant.

The body weight of pups increased linearly with age in all treated groups. There was no difference between treatments (data not shown). The latency to pup-retrieval was significantly increased in the KET exposure group $(20.1 \pm 4.0 \mathrm{~s})$ and the PENT group $(16.4 \pm 4.0)$ on day 9, when compared with the control (vs. KET and PENT; $5.1 \pm 2.3$ ) or Ether (vs. KET; $7.0 \pm 2.6$ ) groups. In mothers with treatments on day 3 , there was no statistical difference among groups (control; $6.9 \pm$ 2.4, Ether; $7.0 \pm 4.0$, KET; $9.1 \pm 1.6$, PENT; $5.1 \pm 1.0$, $\left[F_{(7,71)}=3.145, P=0.0060\right]$; Fig. 1A). Duration of 
Table 1. Behavioral results during a 50 min nursing period after the 4-h isolation of mothers on day 12 of lactation

\begin{tabular}{clrcccccc}
\hline $\begin{array}{c}\text { Day of } \\
\text { Treatments }\end{array}$ & Treatments & $\mathrm{n}$ & $\begin{array}{c}\text { In the nest } \\
\text { with pups (s) }\end{array}$ & $\begin{array}{c}\text { Crouching } \\
(\mathrm{s})\end{array}$ & $\begin{array}{c}\text { Pup-licking } \\
(\mathrm{s})\end{array}$ & $\begin{array}{c}\text { Self-grooming } \\
\text { (frequency) }\end{array}$ & $\begin{array}{c}\text { Stretch reaction } \\
\text { (frequency) }\end{array}$ & $\begin{array}{c}\text { Milk yield } \\
(\mathrm{g})\end{array}$ \\
\hline \multirow{2}{*}{ Day 3} & Control & 11 & $2,478.8 \pm 129.7$ & $1,325.9 \pm 115.5$ & $949.5 \pm 51.4$ & $11.0 \pm 2.2$ & $14.5 \pm 1.3^{\mathrm{a}}$ & $8.33 \pm 0.52$ \\
& Ether & 3 & $2,779.3 \pm 92.0$ & $1,828.0 \pm 424.3$ & $776.0 \pm 246.1$ & $9.3 \pm 4.9$ & $23.0 \pm 5.5^{\mathrm{b}}$ & $5.90 \pm 1.53$ \\
& KET & 8 & $2,512.1 \pm 145.6$ & $1,417.6 \pm 112.5$ & $1,040.4 \pm 101.2$ & $8.0 \pm 1.4$ & $17.4 \pm 1.6^{\mathrm{ab}}$ & $6.14 \pm 0.64$ \\
& PENT & 8 & $2,510.1 \pm 184.0$ & $1,193.8 \pm 80.1$ & $1,094.5 \pm 92.9$ & $11.5 \pm 1.5$ & $15.9 \pm 1.7^{\mathrm{a}}$ & $6.42 \pm 1.20$ \\
Day 9 & Control & 12 & $2,682.4 \pm 122.4$ & $1,623.7 \pm 132.2$ & $840.8 \pm 70.8$ & $10.8 \pm 2.0$ & $14.8 \pm 1.2^{\mathrm{a}}$ & $7.43 \pm 0.60$ \\
& Ether & 6 & $2,465.5 \pm 173.8$ & $1,438.8 \pm 234.4$ & $852.3 \pm 91.1$ & $10.3 \pm 2.3$ & $19.3 \pm 1.2^{\mathrm{b}}$ & $7.52 \pm 0.53$ \\
& KET & 15 & $2,387.6 \pm 106.0$ & $1,338.2 \pm 100.4$ & $933.1 \pm 81.0$ & $14.2 \pm 2.2$ & $18.8 \pm 1.1^{\mathrm{b}}$ & $6.76 \pm 0.58$ \\
& PENT & 16 & $2,556.8 \pm 76.9$ & $1,310.8 \pm 83.7$ & $1,074.9 \pm 86.3$ & $11.9 \pm 1.3$ & $17.4 \pm 0.9^{\mathrm{ab}}$ & $5.92 \pm 0.56$ \\
\hline
\end{tabular}

Means \pm SEM Different letters after data of stretch reaction indicate a significant different between the treatments $(P<0.05)$.

pup-retrieval was altered by treatment with anesthetic drugs. In groups with treatments on day 3 , the duration in the KET group $(68.0 \pm 19.7 \mathrm{~s})$ was significantly longer than in the control (16.5 \pm 4.7$)$ and Ether (19.3 $\pm 4.7)$ groups. KET exposure on day 9 also significantly increased the duration compared with the control $\left(12.3 \pm 4.3,\left[F_{(7,71)}=2.323, P=0.0342\right]\right.$; Fig. 1B). The other components of pup-directed and non pup-directed behavior analyzed in the present study are shown in Table 1. The time that mothers spent in the nest, crouching over pups, pup licking, and other pup-directed activities, was almost the same for all treatments. Self-grooming behavior is ordinarily observed in mothers away from the nest, but mothers also show this behavior in the nest when they are not crouching over the pups to facilitate suckling [30]. In the present experiment, the frequency of self-grooming did not differ between groups. The frequency of the stretching reaction of pups in the Ether group was higher than that in the control, however, the milk yield obtained by each litter was not different between treatments.

The results indicate that exposure to common anesthetic agents altered their behavior towards their young at 3 or 9 days after wakefulness from anesthesia in lactating mothers. The possibility should be considered that the load of anesthetic stress alters aspects of behavioral performance. In the present results, frequency of self-grooming as a non-pup-directed activity of the mother was not increased by exposure to the anesthetic agents. Self-grooming is regarded as a biological index of responsiveness to stress $[3,5,6]$, hypokinesia [24] and anxiety [16] in rats, hence selfgrooming behavior may be an indirect index with which to evaluate emotional status. Moreover, exposure to ether did not alter the maternal performance, while KET and PENT had an impact on it. These results indicate that the type of anesthetic is of importance for the expression of maternal behavior rather than the load of anesthetic stress.

Pup-retrieval was moderately affected by the type of agent, i.e., a difference in the path by which the action takes place, and differences in the postpartum stage of mothers which underwent anesthesia, whereas the other behavior assessed here did not alter with any treatment. A variety of studies using rats with electrolytic and chemical lesions in selected brain regions have demonstrated that active components and nursing behavior in maternal performance are controlled by distinct regions of the central nervous system [11, 12, 14, 17, 18, 28]. Pup-retrieval is considered to be one of the active components, like nest building and pup licking, especially pup-retrieval latency is indicative of maternal motivation $[12,19]$. Anesthesiologically, KET, which has been termed a "dissociative anesthetic", shows markedly different electrical activities from "depressant anesthetics", such as PENT [4]. However, the present results indicate that both anesthetic doses of KET and PENT made the latency to pup-retrieval longer in a timed suckling task 3 days after treatments, suggesting that a common brain region affected by both KET and PENT participates in the expression of pup-retrieval behavior in the established stage of lactation. The present results show that anesthetic agents, especially KET, made the duration of pup-retrieval into the nest much longer, and exposure to KET had long-term effects, i.e. 9 days after exposure. These results suggest 
that the latency and duration of pup-retrieval, which means the onset and continuation of motivated behavior, in lactating rats are controlled by distinct regions or mechanisms of the central nervous system. Our previous finding demonstrated that the latency to the onset and the duration of pup-retrieval in the early stage of lactation in nulliparous rats were significantly longer than those in the established stage of lactation, whereas other pup-directed nursing behavior, such as crouching over the pups in the nest, did not alter between stages [30], suggesting that lactating mothers acquire maternal motivation with the progression of the lactational stage. The results of the present study suggest that presently used general anesthetic drugs have an impact upon the acquisition of maternal motivation with the progression of the maternal stages.

\section{Acknowledgments}

The author wishes to thank Miss Kimiko Meguro, Miss Tomoko Odagiri, Mr. Katsuhiro Takei and Mr. Yu Hara for their technical assistance and animal care. This work was partially supported by Nihon University Individual Research Grant (2004).

\section{References}

1. Aalto, S., Hirvonen, J., Kajander, J., Scheinin, H., Nagren, K., Vilkman, H., Gustafsson, L., Syvalanti, E., and Hietala, J. 2002. Psychopharmacology 164: 401-406.

2. Adams, B.W., Bradberry, C.W., and Moghaddam, B. 2002. Synapse 43: 12-18.

3. Bressers, W.M., Kruk, M.R., van Erp, A.M., WillekensBramer, D.C., Haccou, P., and Meelis, E. 1995. Behav. Neurosci. 109: 1158-1171.

4. Brockmeyer, D.M. and Kendig, J.J. 1995. Br. J. Anaeth. 74: 79-84.

5. Dunn, A.J., Green, E.J., and Isaacson, R.L. 1979. Science 203: 281-283.

6. Ferre, P., Fernandez-Teruel, A., Escorihuela, R.M., Driscoll, P., Corda, M.G., Giorgi, O., and Tobena, A. 1995. Physiol. Behav. 58: 1209-1213.

7. Franks, N.P., Dickinson, R., de Sousa, S.L., Hall, A.C., and Lieb, W.R. 1998. Nature 396: 324.

8. Franks, N.P. and Lieb, W.R. 1994. Nature 367: 607-614.
9. Hancock, P.J. and Stamford, J.A. 1999. Br. J. Anaesth. 82: 603-608.

10. Hansen, S., Bergvall, A.H., and Nyiredi, S. 1993. Pharmacol. Biochem. Behav. 45: 673-676.

11. Hansen, S., Harthon, C., Wallin, E., Lofberg, L., and Svensson, K. 1991. Pharmacol. Biochem. Behav. 39: 7177.

12. Hansen, S. 1994. Physiol. Behav. 55: 615-620.

13. Kamaya, H. and Krishna, P.R. 1987. Anaesthesiology 67: 861-862.

14. Keer, S.E. and Stern, J.M. 1999. Physiol. Behav. 67: 659669.

15. Kegeles, L.S., Martinez, D., Kochan, L.D., Hwang, D.R., Huang, Y., Mawlawi, O., Suckow, R.F., van Heertum, R.L., and Laruelle, M. 2002. Synapse 43: 19-29.

16. Lal, H. and Emmett-Oglesby, M.W. 1983. Neuropharmacology 22: 1423-1441.

17. Lee, A., Clancy, S., and Fleming, A.S. 2000. Behav. Brain. Res. 108: 215-231.

18. Lee, A., Li, M., Watchus, J., and Fleming, A.S. 1999. Behav. Neurosci. 113: 523-538.

19. Li, M. and Fleming, A.S. 2003. Behav. Brain Res. 145: 99-111.

20. Lindefors, N., Barati, S., and O'Connor, W.T. 1997. Brain Res. 759: 205-212.

21. Mantz, J., Varlet, C., Lecharny, J.B., Henzel, D., Lenot, P., and Desmonts, J.M. 1994. Anesthesiology 80: 352-363.

22. Mickley, G.A., Kenmuir, C.L., McMullen, C.A., Snyder, A., Yocom, A.M., Likins-Fowler, D., Valentine, E.L., Weber, B., and Biada, J.M. 2004. BMC Pharmacol. 4: 28.

23. Moghaddam, B., Adams, B., Verma, A., and Daly, D. 1997. J. Neurosci. 17: 2921-2927.

24. Musacchia, X.J., Deavers, D.R., Meininger, G.A., and Davis, T.P. 1980. J. Appl. Physiol. 479-486.

25. Newcomer, J.W., Farber, N.B., Jevtovic-Todorovic, V., Hershey, T., Craft, S., and Olney, J.W. 1999. Neuropharmacology 20: 106-118.

26. Pfaus, J.G., Damsma, G., Nomikos, G.G., Wenkstern, D.G., Blaha, C.D., Phillips, A.G., and Fibiger, H.C. 1990. Brain Res. 530: 345-348.

27. Pfaus, J.G., Damsma, G., Wenkstern, D., and Fibiger, H.C. 1995. Brain Res. 693: 21-30.

28. Vernotica, E.M., Rosenblatt, J.S., and Morrell, J.I. 1999. Behav. Neurosci. 113: 377-390.

29. Wilson, C., Nomikos, G.G., Collu, M., and Fibiger, H.C. 1995. J. Neurosci. 15: 5169-5178.

30. Yamamuro, Y. and Sensui, N. 2000. Anim. Sci. J. 71: 208213.

31. Yilmaz, A., Schulz, D., Aksoy, A., and Canbeyli, R. 2002. Pharmacol. Biochem. Behav. 71: 341-344. 